Originally published as:

Bielaszewska, M., Mellmann, A., Zhang, W., Köck, R., Fruth, A., Bauwens, A., Peters, G., Karch, H. Characterisation of the Escherichia coli strain associated with an outbreak of haemolytic uraemic syndrome in Germany, 2011: A microbiological study

(2011) The Lancet Infectious Diseases, 11 (9), pp. 671-676.

DOI: 10.1016/S1473-3099(11)70165-7

This is an author manuscript.

The definitive version is available at: http://www.sciencedirect.com/ 


\title{
Characterisation of the Escherichia coli strain associated with an outbreak of haemolytic uraemic syndrome in Germany, 2011: a microbiological study
}

\author{
Martina Bielaszewska, $\mathrm{MD}^{\mathrm{a}}$, Alexander Mellmann, $\mathrm{MD}^{\mathrm{a}}$, Wenlan Zhang, $\mathrm{MD}^{\mathrm{a}}$, Robin Köck, $\mathrm{MD}^{\mathrm{a}}$, \\ Angelika Fruth, $\mathrm{PhD}^{\mathrm{b}}$, Andreas Bauwens, $\mathrm{PhD}^{\mathrm{a}}$, Georg Peters, $\mathrm{MD}^{\mathrm{c}}$, Prof Helge Karch, $\mathrm{PhD}{ }^{\mathrm{a}}$, \\ ${ }^{a}$ Institute for Hygiene and the National Consulting Laboratory for Haemolytic Uraemic Syndrome, \\ University of Münster, Münster, Germany \\ ${ }^{\mathrm{b}}$ National Reference Centre for Salmonella and Other Bacterial Enteric Pathogens, Robert Koch \\ Institute, Branch Wernigerode, Wernigerode, Germany \\ ${ }^{c}$ Institute for Medical Microbiology, University of Münster, Münster, Germany
}

\section{Summary}

Background: In an ongoing outbreak of haemolytic uraemic syndrome and bloody diarrhoea caused by a virulent Escherichia coli strain 0104:H4 in Germany (with some cases elsewhere in Europe and North America), 810 cases of the syndrome and 39 deaths have occurred since the beginning of May, 2011. We analysed virulence profiles and relevant phenotypes of outbreak isolates recovered in our laboratory.

Methods: We analysed stool samples from 80 patients that had been submitted to the National Consulting Laboratory for Haemolytic Uraemic Syndrome in Münster, Germany, between May 23 and June 2, 2011. Isolates were screened with standard PCR for virulence genes of Shiga-toxin-producing $\mathrm{E}$ coli and a newly developed multiplex PCR for characteristic features of the outbreak strain $\left(\mathrm{rfb}_{\mathrm{O} 104}\right.$, $\mathrm{fliC}_{\mathrm{H} 4}, \mathrm{stx}_{2}$, and terD). Virulence profiles of the isolates were determined with PCR targeting typical virulence genes of Shiga-toxin-producing $\mathrm{E}$ coli and of other intestinal pathogenic $\mathrm{E}$ coli. We sequenced stx with Sanger sequencing and measured Shiga-toxin production, adherence to epithelial cells, and determined phylogeny and antimicrobial susceptibility.

Findings: All isolates were of the HUSEC041 clone (sequence type 678). All shared virulence profiles combining typical Shiga-toxin-producing $\mathrm{E}$ coli $\left(\mathrm{stx}_{2}\right.$, iha, $\mathrm{Ipf}_{\mathrm{O} 26}, \mathrm{Ipf}_{\mathrm{O} 113}$ ) and enteroaggregative $\mathrm{E}$ coli (aggA, aggR, set1, pic, aap) loci and expressed phenotypes that define Shiga-toxin-producing E coli and enteroaggregative $\mathrm{E}$ coli, including production of Shiga toxing 2 and aggregative adherence to epithelial cells. Isolates additionally displayed an extended-spectrum $\beta$-lactamase phenotype absent in HUSEC041.

Interpretation: Augmented adherence of the strain to intestinal epithelium might facilitate systemic absorption of Shiga toxin and could explain the high progression to haemolytic uraemic syndrome. This outbreak demonstrates that blended virulence profiles in enteric pathogens, introduced into susceptible populations, can have extreme consequences for infected people.

Funding: German Federal Ministry of Education and Research, Network Zoonoses. 


\section{Introduction}

Starting in early May, 2011, an outbreak of haemolytic uraemic syndrome and bloody diarrhoea caused by Escherichia coli O104:H4 has spread throughout Germany. ${ }^{1}$ As of June 20, 2011, 810 cases of haemolytic uraemic syndrome, 2684 non-haemolytic uraemic syndrome cases, and 39 deaths have been reported by the Robert Koch Institute and European Centre for Disease Prevention and Control. The particular features of this outbreak are the predominant involvement of adult women ${ }^{1}$ and common severe neurological complications, such as encephalopathy and epileptic seizures. Almost 100 infections with 39 cases of haemolytic uraemic syndrome caused by the outbreak strain have been reported in other European states including Austria, the Czech Republic, Denmark, France, Greece, Luxemburg, the Netherlands, Norway, Poland, Spain, Sweden (including one death), and the UK and in Canada and the USA - most non-German patients seem to be travellers returning from Germany. In the past 15 years, only a single $E$ coli O104:H4 has been isolated from a patient with haemolytic uraemic syndrome in Germany ${ }^{2}$ (HUSEC041, which is included in the collection of the National Consulting Laboratory for Haemolytic Uraemic Syndrome, University of Münster, Münster, Germany). A single additional case of the syndrome associated with $E$ coli $\mathrm{O} 104: \mathrm{H} 4$ has also been reported from a woman in Korea. ${ }^{3}$ To gain insight into the apparently augmented virulence of the outbreak strain, we analysed virulence profiles and relevant phenotypes of outbreak isolates recovered in our laboratory. We also determined phylogenetic relations of the isolates and their antimicrobial susceptibilities.

\section{Methods}

\section{Stool samples and analysis}

The first stool sample from the suspected outbreak, originating from a patient with haemolytic uraemic syndrome, arrived at the National Consulting Laboratory for Haemolytic Uraemic Syndrome in Münster, Germany on May 23, 2011. By June 2, stools from 79 additional patients including 66 with haemolytic uraemic syndrome and 13 with bloody diarrhoea hospitalised in 22 hospitals in 17 different German cities distributed in nine of 16 federal states were received for microbiological analysis. The strains were isolated by use of stool enrichment in GN broth Hajna, plating the enriched cultures on extended-spectrum $\beta$-lactamase (ESBL) agar plates (chromID ESBL, bioMérieux, Nürtingen, Germany) and cefixime-tellurite sorbitol MacConkey agar (CT-SMAC, Oxoid, Wesel, Germany), and subsequent screening for stx, eae, and EHEC-hlyA with our standard PCR protocol. ${ }^{4}$ In addition, we developed and used multiplex PCR targeting typical molecular features of the outbreak strain ( $r f b_{O 104}$, fli $_{H 4}, s t x_{2}$, and terD; figure 1 and table 1). Multiplex PCR was done with the REDTaq ReadyMix PCR Reaction Mix (Sigma-Aldrich, Taufkirchen, Germany) in a total volume of $25 \mu \mathrm{L}$ containing $2 \mu \mathrm{L}$ of bacterial DNA. PCR conditions included initial denaturation at $94 \mu \mathrm{C}$ for $5 \mathrm{~min}, 30$ cycles of denaturation $\left(94^{\circ} \mathrm{C}, 30 \mathrm{~s}\right)$, annealing $\left(55^{\circ} \mathrm{C}, 60 \mathrm{~s}\right)$, and extension $\left(72^{\circ} \mathrm{C}, 60 \mathrm{~s}\right)$, and final extension at $72^{\circ} \mathrm{C}$ for 5 min. fliC genes of the isolates encoding the $\mathrm{H}$ antigen were subtyped with fliC restriction fragment length polymorphism (RFLP). ${ }^{7}$ HUSEC041 (O104:H4) and HUSEC037 (O104:H21) strains were used for comparison with the outbreak isolates.

\section{Virulence analysis and antimicrobial susceptibility}

Virulence profiles of the outbreak isolates were compared with those of HUSEC041 by use of a set of PCR analyses targeting a broad range of virulence and fitness genes of Shiga-toxin producing $E$ coli [5], [6], [7], [8], [9], [10], [11], , [12] and [13] that typically cause haemolytic uraemic syndrome, ${ }^{14}$ such as those encoding toxins ( $s t x_{1}, s t x_{2}$, EHEC-hlyA, cdt, subAB), serine proteases (espP), adhesins (eae, iha, IpfA $A_{O 26}, I p f A_{O 113}, I p f A_{O 157-01441}, I p f A_{O 157-01154}$, saa, sfpA), iron acquisition system encoded on high pathogenicity island (marker genes irp2 and fyuA), and tellurite resistance (terD as a marker for the ter cluster). All isolates were PCR-tested for virulence loci typical for other intestinal pathogenic $E$ coli including enteropathogenic (bfpA encoding structural subunit of bundle-forming pili), enterotoxigenic (elt and estl encoding heat-labile and heat-stable enterotoxin, respectively), enteroinvasive (ial, a marker for the virulence plasmid plnv), and enteroaggregative $E$ coli (ast $A$, sen, set1, and pic encoding toxins, aggA, aafA, agg3A, and agg $4 A$ encoding adhesins, agg $R$ encoding transcription regulator, aap encoding dispersin, and aat as a marker for enteroaggregative $E$ coli virulence plasmid). ${ }^{[15],[16], ~[17], ~[18], ~}$ [19] and [20] 
stx genes of four outbreak isolates from four different cities were amplified and Sanger sequenced; resulting sequences were analysed with the Ridom TraceEditPro Software (Ridom GmbH, Münster, Germany) and homologies were sought in GenBank.

The isolates were confirmed as $E$ coli (API $20 \mathrm{E}$, bioMérieux) and serotyped. ${ }^{21} \beta$-D-glucuronidase activity was assessed by use of nutrient agar with 4-methylumbelliferyl- $\beta$-D-glucuronide (Becton Dickinson, Heidelberg, Germany). Production of enterohaemorrhagic $E$ coli haemolysin was sought on enterohaemolysin agar (Sifin, Berlin, Germany), and production of a haemolysin on Columbia blood agar (Heipha, Heidelberg, Germany). Resistance to tellurite was determined by ability to grow on CTSMAC. Shiga-toxin production was identified with the Vero cell cytotoxicity assay. ${ }^{4}$ Adherence to human intestinal epithelial cells (HCT-8; ATCC CCL-244) was tested as described previously ${ }^{22}$ by use of semiconfluent monolayers incubated with the strains for $3 \mathrm{~h}$ in the presence of $0.5 \% \mathrm{D}$-mannose. Bacterial adherence patterns were examined with phase-contrast microscopy (AxiolmagerA1; Zeiss, Jena, Germany) of washed, fixed, and Giemsa-stained cells.

Antimicrobial susceptibility was determined by use of the Vitek 2 system version 05.02 (bioMérieux). Minimum inhibitory concentrations were interpreted in accordance with EUCAST 2010 guidelines. ${ }^{23}$

\section{Genetic analysis}

Multilocus sequence typing (MLST) was done by sequencing internal fragments of seven housekeeping genes (adk, fumC, gyrB, icd, $m d h$, purA, and recA) ${ }^{24}$ The alleles and sequence type (ST) were assigned in accordance with the $E$ coliMLST databases at the Environmental Research Institute, University College Cork, Ireland. In addition to MLST, all strains were subjected to partial gnd sequencing (627 bp internal gnd gene fragment, positions 397-1023 in strain W3110, GenBank accession number AP009048) in accordance to the protocol of Gilmour and colleagues ${ }^{25}$ Three reference E coli O104 strains including HUSEC041 (O104:H4), HUSEC037 (O104:H21), and enteroaggregative E coli strain 55989 (O104:H4; GenBank accession number NC_011748) were included as controls. The partial gnd sequence enables prediction of the O-phase of $E$ coli. ${ }^{25}$

\section{Role of the funding source}

The funding institutions had no role in the study design, data collection, analysis and interpretation, writing the Article or decision for publication. The corresponding author had full access to all the data in the study and final responsibility for the decision to submit for publication.

\section{Results}

The first outbreak strain (LB226692) was isolated in the German National Consulting Laboratory for Haemolytic Uraemic Syndrome in Münster on May 24, 2011. Molecular analysis of the isolate with PCR detected an $s x_{2}$-positive, eae-negative Shiga-toxin-producing $E$ coli, which was further characterised by sequence analysis of $g$ nd, fliC RFLP, and MLST as gnd $_{\mathrm{O} 104}, \mathrm{fli}_{\mathrm{H} 4}$, and ST678. Moreover, the strain grew on CT-SMAC and possessed ter cluster encoding tellurite resistance. These characteristics of the isolate enabled us to develop the multiplex PCR targeting the typical molecular features of the strain $\left(r \mathrm{fb}_{\mathrm{O} 104}, \mathrm{fliC}_{\mathrm{H} 4}, \mathrm{st} \mathrm{x}_{2}\right.$, and terD; figure 1), which we then used for identification of the subsequent outbreak isolates. We proved specificity of the multiplex PCR by showing that, among the 42 reference strains of the HUSEC collection and 100 additional Shiga-toxin-producing $E$ coli of various serotypes as well as E coli from normal intestinal flora, only HUSEC041 gave amplicons for all the four loci targeted by the multiplex PCR.

All 80 outbreak isolates possessed $r f b_{O 104}$ belonging to the $\mathrm{O} 104$ biosynthetic cluster and $\mathrm{fli}_{\mathrm{H} 4}$ belonging to the $\mathrm{H} 4$ antigen biosynthetic cluster, as determined by multiplex PCR (figure 1). gnd of all isolates was identical in the 627 bp sequenced fragment and it was identical to gnd of the two 0104 reference strains in the HUSEC collection (HUSEC037 and HUSEC041) and of strain 55989 (GenBank accession number NC_011748), corroborating the O104 lipopolysaccharide phenotype. Presence of $f l i \mathrm{C}_{\mathrm{H} 4}$ was verified using RFLP. All 80 isolates belonged to serotype O104: $\mathrm{H} 4$. All of them 
produced $\beta$-D-glucuronidase, fermented sorbitol and were tellurite resistant, and none produced enterohaemorrhagic $E$ coli haemolysin or a haemolysin. All 80 isolates belonged to ST678, as does HUSEC041. This sequence type is unique to serotype O104:H4 among Shiga-toxin-producing E coli. On the basis of MLST, gnd sequence, and presence of $f l i C_{H 4}$ we concluded that the isolates were a single clone.

Each of the 80 outbreak isolates possessed virulence genes typical of Shiga-toxin-producing $E$ coli, including $s t x_{2}$ encoding the toxin, iha, $I p f_{O 26}$, and $l p f_{O 113}$ encoding adhesins, and the high pathogenicity island originally identified in Yersiniae and encoding an iron uptake system $;{ }^{13}$ eae encoding adhesin intimin ${ }^{15}$ was not present (table 2). The $s x_{2}$ sequence was identical in four randomly chosen outbreak isolates and was $99 \%$ homologous to $s t x_{2}$ sequence of prototypic Shiga-toxin-producing $E$ coli O157:H7 strain EDL933 (GenBank AE005174), with one synonymous nucleotide change in each subunit gene $\left(s t \times A_{2}\right.$ and $\left.s t \times B_{2}\right)$. Moreover, all isolates possessed typical molecular characteristics of

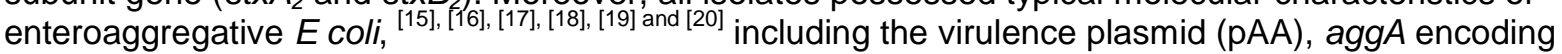
structural subunit of aggregative adherence fimbriae I (AAF/I), aggR encoding the enteroaggregative $E$ coli global regulator AggR, aap encoding dispersin, set1 encoding Shigella enterotoxin 1, and pic encoding an autotransporter serine protease (protein involved in intestinal colonisation). None of the isolates contained ast $A$ encoding enteroaggregative $E$ coli heat-stable enterotoxin 1 (table 2). The absence of ast $A$ and the presence of the genes encoding AAF/I fimbriae differentiate, among the 34 alleles investigated, the outbreak isolates from HUSEC041, which contains ast $A$ as well as agg3A encoding the structural subunit of AAF/III fimbriae (table 2). These loci are also present in the reference enteroaggregative $E$ coli strain 55989 (table 2). The results of the PCR analyses are concordant with the draft genome data of an outbreak isolate LB226692 (NCBI accession number AFPS01000000) after in-silico analysis of primer binding sites and the resulting fragment length determination.

In addition to harbouring a mixture of virulence loci of two different intestinal $E$ coli pathotypes, all O104:H4 outbreak isolates also express the phenotypes that define Shiga-toxin-producing $E$ coli and enteroaggregative $E$ coli, ${ }^{[15]}$ and [16] specifically production of Shiga-toxin 2 (Vero cell cytotoxicity titres 64-1024; median 256) and the aggregative (so-called stacked-brick) adherence pattern on intestinal epithelial cells (figure 2). The aggregative adherence phenotype (figure 2) combined with Shiga-toxin 2 production (Vero cell titre 64) are also displayed by HUSEC041. Virulence loci typically found in other intestinal pathogenic $E$ coli including enteropathogenic, enteroinvasive, and enterotoxigenic $E$ coli are absent from the O104:H4 outbreak isolates and from HUSEC041 (table 2).

All isolates have an ESBL phenotype-ie, they are resistant to all penicillins and cephalosporins and susceptible to carbapenems (ertapenem, imipenem, meropenem). This resistance pattern is typical for CTX-M-1 group $\beta$ lactamases and corroborates the already reported findings of the CTX-M-15 genotype ${ }^{26}$ Furthermore, all strains are resistant to co-trimoxazole (trimethoprim-sulfamethoxazole) and susceptible to fluoroquinolones (ciprofloxacin) and aminoglycosides (gentamicin, tobramycin). HUSEC041 did not have the ESBL phenotype.

\section{Discussion}

The genotypes, phenotypes, and phylogeny of the 80 outbreak isolates demonstrate that the $E$ coli O104: $\mathrm{H} 4$ outbreak strain is a clone that combines virulence potentials of two different pathogens: Shiga-toxin-producing $E$ coli and enteroaggregative $E$ coli (panel). HUSEC041, isolated in 2001 from a child with haemolytic uraemic syndrome in Germany, also had this virulence combination. 
Panel. Research in context

Search strategy

We searched the PubMed database for papers published in English between Jan 1, 1990, and June 14, 2011, with the search terms "O104", "O104: H4", "HUS" (haemolytic uraemic syndrome), "enteroaggregative", or "enterohaemorrhagic". No articles provided a comprehensive characterisation of the enterohaemorrhagic Escherichia coliO104:H4 causing a large outbreak in Germany

\section{Interpretation}

E col/ 0104: $\mathrm{H} 4$, which has characteristics and genetic loci found in Shiga-toxin-producing $E$ coli and enteroaggregative $E$ coli, is unprecedented among enteric pathogens in its virulence. This isolate belongs to the rare sequence type 678 and produces Shiga toxin 2 and aggregative adherence to intestinal epithelial cells. This pathogen, and this outbreak, will have profound implications for disease detection, reporting, food safety, and our understanding of microbial pathogenesis.

\section{Search strategy}

We searched the PubMed database for papers published in English between Jan 1, 1990, and June 14, 2011, with the search terms "O104", "O104:H4", "HUS" (haemolytic uraemic syndrome), "enteroaggregative", or "enterohaemorrhagic". No articles provided a comprehensive characterisation of the enterohaemorrhagic Escherichia coli O104:H4 causing a large outbreak in Germany.

\section{Interpretation}

E coli $0104: \mathrm{H} 4$, which has characteristics and genetic loci found in Shiga-toxin-producing $E$ coli and enteroaggregative $E$ coli, is unprecedented among enteric pathogens in its virulence. This isolate belongs to the rare sequence type 678 and produces Shiga toxin 2 and aggregative adherence to intestinal epithelial cells. This pathogen, and this outbreak, will have profound implications for disease detection, reporting, food safety, and our understanding of microbial pathogenesis.

Isolation of this rare $E$ coli $\mathrm{O} 104: \mathrm{H} 4$ serotype in many samples and in a short time confirms that this is the outbreak strain; however, we do not have access to the entire strain collection from this outbreak because no single laboratory has statutory authority for the analysis or possession of these isolates. Because of the rapidly increasing number of infected people and the severity of the disease, identification and profiling of the outbreak strain as expeditiously as possible was essential. In this race against time, sequence analysis of $g$ nd, identification of ST678 (which is unique to serotype O104:H4 among Shiga-toxin-producing $E$ coli, until now reported only in the HUSEC041 reference strain from 2001), and identification of fliC $_{H_{4}}$ together with the presence of $s t x_{2}$ were the crucial points in determining the novelty of the strain just 2 days after the first stool arrived. This is of particular importance because in addition to $E$ coli $\mathrm{O} 104: \mathrm{H} 4$, there are also other Shiga-toxin-producing $E$ coli of serogroup $\mathrm{O} 104$, but these possess different $\mathrm{H}$ antigen. ${ }^{27}$ The most common is Shiga-toxin-producing E coli O104:H21 represented in our HUSEC collection by HUSEC037. An O104:H21 strain, which is similar to the $E$ coli $\mathrm{O} 104: \mathrm{H} 4$ outbreak strain, also eae-negative, caused an outbreak of bloody diarrhoea associated with consumption of raw milk in Montana, USA, in $1994{ }^{28}$

Taken together, the availability of the HUSEC collection including representative, well-characterised (genotypically and phenotypically) Shiga-toxin-producing $E$ coli strains of all serotypes associated with haemolytic uraemic syndrome in Germany during the past 15 years and of gnd sequencing, fliC-RFLP and MLST enabled us in a very short time to identify the outbreak isolates as $E$ coli O104:H4. These data and the rapidity with which the outbreak strain has been characterised show the value of standing collections of well characterised pathogens with known provenance, which was the purpose of the HUSEC collection. Moreover, implementation of well established, reproducible, and independent techniques, such as PCR and phenotypic tests available in our laboratory [4], [5], [6], [8], [12] and [22] enabled 
further rapid characterisation of the outbreak strain. The outbreak strain, which is a sorbitol fermenter, would have been missed by standard diagnostic procedures focused on the $0157: \mathrm{H} 7$ strain and using SMAC to identify this organism on the basis of its lack of sorbitol fermentation. However, the ESBL resistance of the outbreak strain aided its recovery from patients' stool samples by use of culture on ESBL agar. This feature might be used to seek reservoirs of this strain and to recover the organism from suspected vehicles of transmission.

The reason for the apparently augmented virulence potential of the outbreak O104:H4 strain, as indicated by the high amount of haemolytic uraemic syndrome cases and 39 deaths, is unknown, but our data suggest some possibilities. The enhanced adherence of this strain to intestinal epithelial cells (figure 2) might facilitate systemic absorption of Shiga toxin and could explain the high frequency of progression to haemolytic uraemic syndrome. Antibiotic resistance might also play a part if $\beta$-lactam drugs used to treat the infection suppressed competing microbiota. When the outbreak strain acquired a plasmid encoding CTX-M-15, which is absent in the original HUSECO41 isolate from 2001, is unknown. This plasmid has been identified in several different genera in the Enterobacteriaceae. ${ }^{29}$ Our data do not permit us to state if the Shiga-toxin-producing and enteroaggregative traits in $E$ coli 0104: $\mathrm{H} 4$ combined recently, or if this pathogen is coming to light now because of conditions suitable for its spread. An E coli O111 strain that expressed Shiga toxin and displayed an aggregative adherence on epithelial cells ${ }^{30}$ caused an outbreak of haemolytic uraemic syndrome in France 15 years ago, ${ }^{31}$ but the number of cases (ten) was lower than in the ongoing German outbreak ( 810 as of June 20). Differences in virulence potentials of the 0111 and 0104 outbreak strains, modes of transmission, the infectious dose present in the vehicle of infection (recently, sprouts have been identified as a source of the German outbreak), ${ }^{32}$ and general susceptibilities of the human hosts to these two strains might play a part. Although we lack an explanation for increased virulence, this outbreak tragically shows that blended virulence profiles in enteric pathogens introduced into susceptible populations can have serious consequences for infected people.

\section{Contributors}

$\mathrm{MB}$ and $\mathrm{HK}$ designed the study, analysed the data and wrote the paper. AM and RK isolated and AF serotyped the strains. AM, RK, and GP did the antimicrobial sensitivity tests. WZ developed and did the multiplex PCR for identification of $E$ coli O104: $\mathrm{H} 4$. MB and WZ did the genomic analyses, and $\mathrm{AB}$ and $M B$ the phenotypic studies. AB prepared the figures. HK and AM raised the funding. HK and GP supervised the study.

\section{Conflicts of interest}

We declare that we have no conflicts of interest.

\section{Acknowledgements}

\section{Acknowledgments}

We thank Phillip I Tarr (Washington University School of Medicine, St Louis, MO, USA) for extensive discussions of the Article. We also thank Nadine Brandt, Margret Junge, Ralph Fischer, and Andrea Lagemann for technical assistance. This study was supported by grants from the Federal Ministry of Education and Research Network Zoonoses (no 01KI07124 and 01KI07127, and PBA-Zoo project grant No. 01Kl1020) and by the Medical Faculty of the University of Münster (grant BD9817044). 


\section{References}

1. Frank C, Faber MS, Askar M, et al. Large and ongoing outbreak of haemolytic uraemic syndrome, Germany, May 2011. Euro Surveill 2011; 16: pii=19878. Published online May 26, $2011 \mathrm{http}: / / \mathrm{www}$. eurosurveillance.org/ViewArticle.aspx?Articleld=19878 (accessed June 1, 2011).

2. Mellmann A, Bielaszewska M, Kock R, et al. Analysis of collection of hemolytic uremic syndromeassociated enterohemorrhagic Escherichia coli. Emerg Infect Dis 2008; 14: 1287-90.

3. Bae WK, Lee YK, Cho MS, et al. A case of hemolytic uremic syndrome caused by Escherichia coli 104:H4. Yonsei Med J 2006; 47: 437-39.

4. Bielaszewska M, Friedrich AW, Aldick T, Schurk-Bulgrin R, Karch H. Shiga toxin activatable by intestinal mucus in Escherichia coli isolated from humans: predictor for a severe clinical outcome. Clin Infect Dis 2006; 43: 1160-67.

5. Bielaszewska M, Zhang W, Tarr PI, Sonntag AK, Karch H. Molecular profi ling and phenotype analysis of Escherichia coli O26:H11 and O26:NM: secular and geographic consistency of enterohemorrhagic and enteropathogenic isolates. J Clin Microbiol 2005; 43: 4225-28.

6. Bielaszewska M, Tarr PI, Karch H, Zhang W, Mathys W. Phenotypic and molecular analysis of tellurite resistance among enterohemorrhagic Escherichia coli O157:H7 and sorbitol-fermenting O157:NM clinical isolates. J Clin Microbiol 2005; 43: 452-54.

7. Zhang W, Mellmann A, Sonntag AK, et al. Structural and functional differences between diseaseassociated genes of enterohaemorrhagic Escherichia coli O111. Int J Med Microbiol 2007; 297: 1726.

8. Bielaszewska M, Fell M, Greune L, et al. Characterization of cytolethal distending toxin genes and expression in Shiga toxin-producing Escherichia coli strains of non-O157 serogroups.

Infect Immun 2004; 72: 1812-16.

9. Paton AW, Paton JC. Direct detection and characterization of Shiga toxigenic Escherichia coli by multiplex PCR for stx1, stx2, eae, exhA, and saa. J Clin Microbiol 2002; 40: 271-74.

10. Paton AW, Srimanote P, Talbot UM, Wang H, Paton JC. A new family of potent AB5 cytotoxins produced by Shiga toxigenic Escherichia coli. J Exp Med 2004; 200: 35-46.

11. Toma C, Martinez Espinosa E, Song T, et al. Distribution of putative

adhesins in diff erent seropathotypes of Shiga toxin-producing Escherichia coli. J Clin Microbiol 2004; 42: 4937-46.

12. Friedrich AW, Nierhoff KV, Bielaszewska M, Mellmann A, Karch H. Phylogeny, clinical associations, and diagnostic utility of the pilin subunit gene $(\operatorname{sfpA})$ of sorbitol-fermenting, enterohemorrhagic Escherichia coli O157:H-. J Clin Microbiol 2004; 42: 4697-01.

13. Karch $\mathrm{H}$, Schubert $\mathrm{S}$, Zhang $\mathrm{D}$, et al. A genomic island, termed high pathogenicity island, is present in certain non-O157 Shiga toxin-producing Escherichia coli clonal lineages. Infect Immun 1999; 67: 5994-01.

14. Karch H, Tarr PI, Bielaszewska M. Enterohaemorrhagic Escherichia coli in human medicine. Int J Med Microbiol 2005; 295: 405-18.

15. Nataro JP, Kaper JB. Diarrheagenic Escherichia coli. Clin Microbiol Rev 1998; 11: 142-201.

16. Kaper JB, Nataro JP, Mobley HL. Pathogenic Escherichia coli. Nat Rev Microbiol 2004; 2: 123-40.

17. Okeke IN, Nataro JP. Enteroaggregative Escherichia coli.

Lancet Infect Dis 2001; 1: 304-13.

18. Vila J, Vargas M, Henderson IR, Gascon J, Nataro JP. Enteroaggregative Escherichia coli virulence factors in traveler's diarrhea strains. J Infect Dis 2000; 182: 1780-83.

19. Muller D, Greune L, Heusipp G, et al. Identifi cation of unconventional intestinal pathogenic Escherichia coli isolates expressing intermediate virulence factor profi les by using a novel single-step multiplex PCR. Appl Environ Microbiol 2007; 73: 3380-90.

20. Boisen N, Struve C, Scheutz F, Krogfelt KA, Nataro JP. New adhesin of enteroaggregative Escherichia coli related to the Afa/Dr/AAF family. Infect Immun 2008; 76: 3281-92.

21. Prager R, Strutz U, Fruth A, Tschape H. Subtyping of pathogenic Escherichia coli strains using fl agellar (H)-antigens: serotyping versus fl iC polymorphisms. Int J Med Microbiol 2003; 292: 477-86. 22. Aldick T, Bielaszewska M, Zhang W, et al. Hemolysin from Shiga toxin-negative Escherichia coli O26 strains injures microvascular endothelium. Microbes Infect 2007; 9: 282-90.

23. European Committee on Antimicrobial Susceptibility Testing. Breakpoint tables for interpretation of MICs and zone diameters. http://www.eucast.org/fi leadmin/src/media/PDFs/EUCAST_fi les/

Disk_test_documents/EUCAST_breakpoints_v1.3_pdf (accessed June 20, 2011).

24. Wirth T, Falush D, Ruiting L, et al. Sex and virulence in Escherichia coli: an evolutionary perspective. Mol Microbiol 2006; 60: 1136-51.

25. Gilmour MW, Olson AB, Andrysiak AK, Ng L, Chui L. Sequencebased typing of genetic targets encoded outside of the O-antigen gene cluster is indicative of Shiga toxin-producing Escherichia coli 
serogroup lineages. J Med Microbiol 2007; 56: 620-28.

26. Robert Koch Institute. Aktualisierte Hinweise und Hilfestellungen des RKI zur Diagnostik des gegenwartig zirkulierenden Ausbruchstammes. http://www.rki.de/cln_144/nn_467482/DE/

Content/InfAZ/E/EHEC/EHEC_Diagnostik,templateld=raw,property=publicationFile.pdf/EHEC_Diagn ostik.pdf (accessed June 20, 2011).

27. European Centre for Disease Prevention and Control and European Food Safety Authority. Shiga toxin/verotoxin-producing Escherichia coli in humans, food and animals in the EU/EEA, with special reference to the German outbreak strain STEC 0104. Stockholm: ECDC; 2011.

28. Centers for Disease Control and Prevention. Outbreak of acute gastroenteritis attributable to Escherichia coli serotype O104:H21-Helena, Montana, 1994. MMWR Morb Mortal Wkly Rep 1995; 44: 501-03.

29. Bonnet R. Growing group of extended-spectrum $\beta$-lactamases: the CTX-M enzymes. Antimicrob Agents Chemother 2004; 48: 1-14.

30. Morabito S, Karch H, Mariani-Kurkdjian P, et al. Enteroaggregative, Shiga toxin-producing Escherichia coli $\mathrm{O} 111: \mathrm{H} 2$ associated with an outbreak of hemolytic-uremic syndrome. J Clin Microbiol 1998; 36: 840-42.

31. Boudaillez B, Berquin P, Mariani-Kurkdjian P, et al. Possible person-to-person transmission of Escherichia coli O111-associated hemolytic uremic syndrome. Pediatr Nephrol 1996; 11: 36-39.

32. Bundesinstitut fur Risikobewertung. EHEC outbreak: BfR confi rms contamination of sprouts with O104:H4. Federal Institute for Risk Assessment (BfR) Germany, 2011. Published online June 11, 2011

http://www.bfr.bund.de/de/presseinformation/2011/17/ehec_ausbruch_bfr_bestaetigt_kontamination_ von_sprossen_mit_0104_h4-70934.html (accessed June 11, 2011). 


\section{Tables and Figures}

Table 1. Primers for multiplex PCR to identify Escherichia coli O104:H4 harbouring stx

\begin{tabular}{|c|c|c|c|c|c|}
\hline & Sequence $\left(5^{\prime}-3\right)$ & Target & $\begin{array}{l}\text { Amplicon size } \\
\text { (bp) }\end{array}$ & $\begin{array}{l}\text { Primer } \\
\text { concentration }\end{array}$ & Reference \\
\hline $\begin{array}{l}\text { 0104rfbof } \\
\text { O104rfbOr }\end{array}$ & $\begin{array}{l}\text { TGAАСTGATTTTAGGATGG } \\
\text { АGААССТСАСTСАААTTATG }\end{array}$ & rbo:m4 & 351 & $360 \mathrm{nmol} / \mathrm{L}$ & This study \\
\hline $\begin{array}{l}\text { flich4-a } \\
\text { flicH4-b }\end{array}$ & $\begin{array}{l}\text { GGCGAAACTGACGGCTGCTG } \\
\text { GCACCAACAGTTACCGCCGC }\end{array}$ & $f W C_{H 4}$ & 201 & $240 \mathrm{nmol} / \mathrm{L}$ & This study \\
\hline $\begin{array}{l}\text { LP43 } \\
\text { LP44 }\end{array}$ & $\begin{array}{l}\text { АTCCTATTCCCGGGAGTTACG } \\
\text { GCGTCATCGTATACACAGGAGC }\end{array}$ & st $x_{2}$ & 584 & $150 \mathrm{nmol} / \mathrm{L}$ & 5 \\
\hline $\begin{array}{l}\text { TerD1 } \\
\text { TerD2 }\end{array}$ & $\begin{array}{l}\text { AGTAAAGCAGCTCCGTCAAT } \\
\text { CCGAACAGCATGGCAGTCT }\end{array}$ & $\operatorname{ter} \theta$ & 434 & 240 nmolíl & 6 \\
\hline
\end{tabular}

Multiplex PCR with initial denaturation $\left(94^{\circ} \mathrm{C}, 5 \mathrm{~min}\right), 30$ cycles of denaturation $\left(94^{\circ} \mathrm{C}, 30 \mathrm{~s}\right)$, annealing $\left(55^{\circ} \mathrm{C}, 60 \mathrm{~s}\right)$, and extension $\left(72^{\circ} \mathrm{C}, 60 \mathrm{~s}\right)$, and final extension $\left(72^{\circ} \mathrm{C}, 5 \mathrm{~min}\right)$ 
Table 2. Virulence loci of 80 Escherichia coli O104:H4 outbreak isolates by pathogroup, compared with HUSEC041 and enteroaggregative E coli strain 55989

\begin{tabular}{|c|c|c|c|c|}
\hline & Product & $\begin{array}{l}\text { Presence in } E \\
\text { cos } 0104: \mathrm{H}^{4}\end{array}$ & $\begin{array}{l}\text { Presence in } \\
\text { HUSEC041 }\end{array}$ & $\begin{array}{l}\text { Presence in } \\
\text { EAEC } 55989^{+}\end{array}$ \\
\hline \multicolumn{5}{|l|}{ STEC } \\
\hline$s t x_{i}$ & Shiga toxin 1 & $0 / 80$ & No & No \\
\hline stoxz & Shiga toxin 2 & $80 / 80$ & Yes & No \\
\hline $\mathrm{EHEC}-\mathrm{h} / \mathrm{y} / \mathrm{A}$ & EHEC haemolysin & 0,80 & No & No \\
\hline $\cot (1-V)$ & Cytolethal distending toxin & 0,80 & No & No \\
\hline$S \omega b A B$ & Subtilase cytotoxin & $0 / 80$ & No & No \\
\hline espop & Serine protease EspP & 0,80 & No & No \\
\hline eqe & Intimin & $0 / 80$ & No & No \\
\hline Dhe & Iha (IrgA homologue adhesin) & $80 / 80$ & Yes & Yes \\
\hline $10.4 f_{O}: 6$ & $\begin{array}{l}\text { Structural subunit of long polar } \\
\text { fimbriae (LPF) of STEC O26 }\end{array}$ & $80 / 80$ & Yes & Yes \\
\hline Sof $A_{0} n s$ & $\begin{array}{l}\text { Structural subunit of LPF of STEC } \\
0113\end{array}$ & $80 / 80$ & Yes & Yes \\
\hline $105 A_{0} 0167-01145$ & $\begin{array}{l}\text { Structural subunit of LPF of STEC } \\
0157: \mathrm{H} 7 \text { (encoded on O island 141) }\end{array}$ & $0 / 80$ & No & No \\
\hline $107 A_{0} 667-01664$ & $\begin{array}{l}\text { Structural subunit of LPF of STEC } \\
0157: \mathrm{H} 7 \text { (encoded on O island 154) }\end{array}$ & $0 / 80$ & No & No \\
\hline sas & $\begin{array}{l}\text { Saa (STEC autoagglutinating } \\
\text { adhesin) }\end{array}$ & $0 / 80$ & No & No \\
\hline sfo $A$ & Structural subunit of Sfp fimbriae & $0 / 80$ & No & No \\
\hline fer cluster & Tellurite resistance & $80 / 80$ & Yes & No \\
\hline iro2 & $\begin{array}{l}\text { Component of iron uptake system on } \\
\mathrm{HPI}\end{array}$ & $80 / 80$ & Yes & No \\
\hline$f y u A$ & $\begin{array}{l}\text { Component of iron uptake system on } \\
\mathrm{HPI}\end{array}$ & $80 / 80$ & Yes & No \\
\hline \multicolumn{5}{|l|}{ EAEC } \\
\hline$a a t A$ & EAEC virulence plasmid $(p, A) \mp$ & $80 / 80$ & Yes & Yes \\
\hline $\operatorname{sgg} A$ & $\begin{array}{l}\text { Pilin subunit of aggregative } \\
\text { adherence fimbriae I (A.AF/I) }\end{array}$ & $80 / 80$ & No & No \\
\hline $\operatorname{sgg} 3 A$ & $\begin{array}{l}\text { Pilin subunit of aggregative } \\
\text { adherence fimbriae III (AAF/III) }\end{array}$ & $0 / 80$ & Yes & Yes \\
\hline $\operatorname{sgg} R$ & Transcriptional regulator $\mathrm{AggR}$ & 80880 & Yes & Yes \\
\hline$a a p$ & Dispersin & 80880 & Yes & Yes \\
\hline setf & Shigells enterotoxin 1 & $80 / 80$ & Yes & Yes \\
\hline pic & $\begin{array}{l}\text { Pic (protein involved in intestinal } \\
\text { colonisation) }\end{array}$ & $80 / 80$ & Yes & Yes \\
\hline astA & $\begin{array}{l}\text { EAEC heat-stable enterotoxin } 1 \\
\text { (EAST1) }\end{array}$ & $0 / 80$ & Yes & Yes \\
\hline \multicolumn{5}{|l|}{ EPEC } \\
\hline$b F D A$ & Bundle-forming pili & $0 / 80$ & No & No \\
\hline \multicolumn{5}{|l|}{ ETEC } \\
\hline$e$ ef & Heat-labile enterotoxin ( $L T)$ & $0 / 80$ & No & No \\
\hline estis & Heat-stable enterotoxin (STla) & $0 / 80$ & No & No \\
\hline estib & Heat-stable enterotoxin (STIb) & $0 / 80$ & No & No \\
\hline \multicolumn{5}{|l|}{ EIEC } \\
\hline is & Invasive plasmid (plnv) $)^{5}$ & 0,80 & No & No \\
\hline STEC $=$ Shiga & toxin-producing. $\quad E P E C=e n t e r o p a t h$ & $E A E C=e r$ & eroaggregative. & ETEC=enterotoxigenic \\
\hline \multicolumn{5}{|c|}{$\mathrm{EIEC}=$ enteroinvasive $E_{\operatorname{cof}} . \mathrm{HPI}=$ high pathogenicity island. } \\
\hline \multicolumn{5}{|c|}{ Number of strains positive for the locusinumbertested. } \\
\hline \multicolumn{5}{|c|}{ Based on in silico analysis of the sequence of EAEC strain 55989 (GenBank accession number NC_011748). } \\
\hline \multicolumn{5}{|c|}{ Tested by PCR targeting the region of the EAEC virulence plasmid used as an EABEC diagnostic probe (pCVD432) for $¥ z A A$} \\
\hline Tested by $\mathrm{PC}$ & CRtargeting the region of pinvused as an EIEC & diagnostic probe (ial). & & \\
\hline
\end{tabular}


Figure 1. Detection of Escherichia coli $\mathrm{O} 104: \mathrm{H} 4$ outbreak strainThe amplicons are $s t x_{2}$ (584 bp), terD

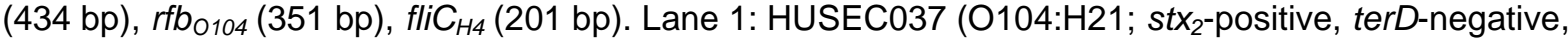
$\mathrm{rfb}_{\mathrm{O} 104}$-positive, fliC $\mathrm{H}_{\mathrm{H}}$-negative). Lanes 2 and 3: $\mathrm{E}$ coli O104:H4 outbreak isolates LB226692 and LB226541, respectively. Lane 4: E coli K12 negative control. Lane 5: reagent control. M: $100 \mathrm{~kb}$ molecular size marker.

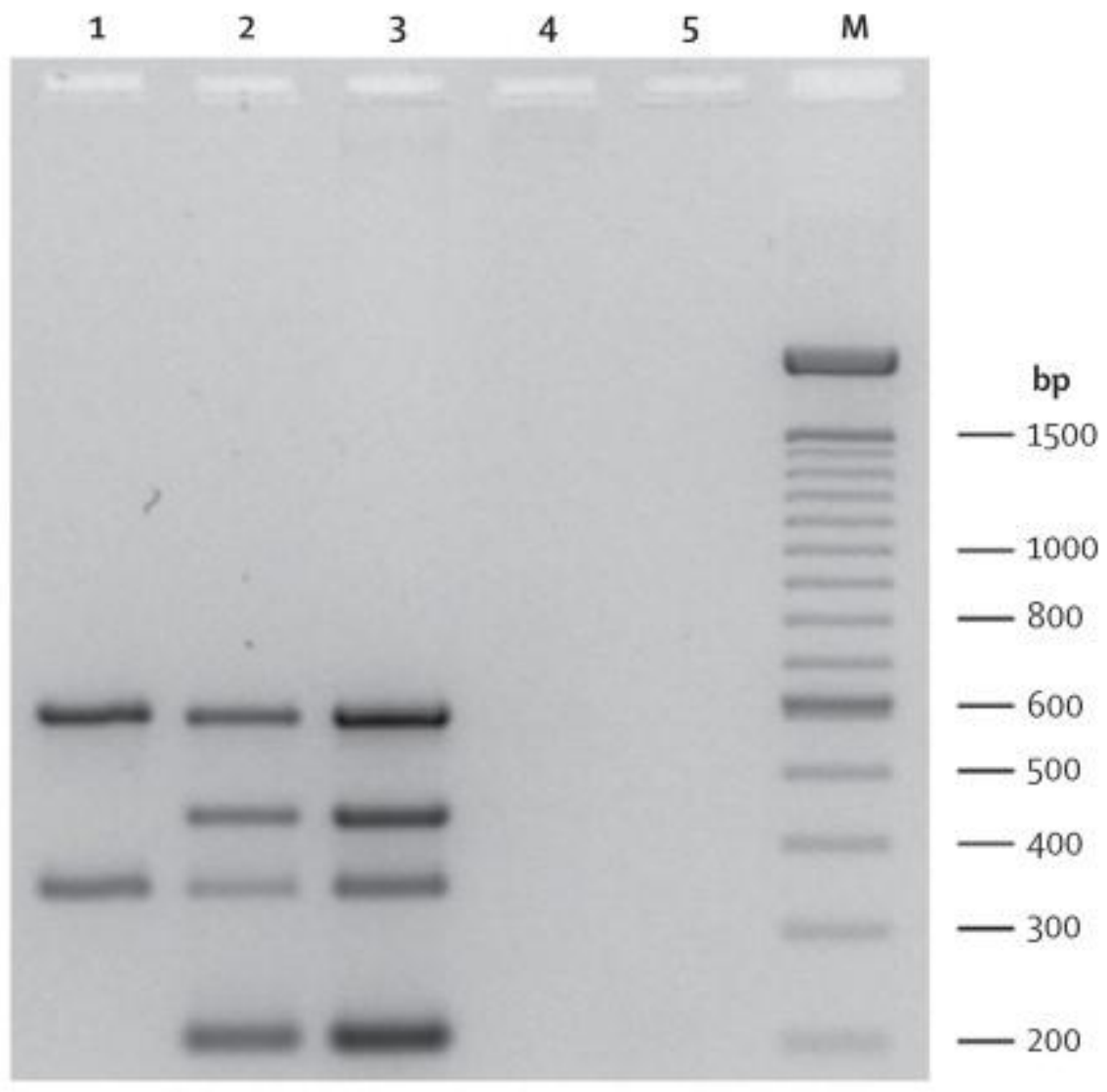


Figure 2. Aggregative, so called, stacked-brick adherence to cultured intestinal epithelial cellsOutbreak Escherichia coli O104:H4 isolate LB226692 (A). An enteroaggregative E coli strain (positive control; B). HUSEC041 (C). HUSEC037 (negative control; D).

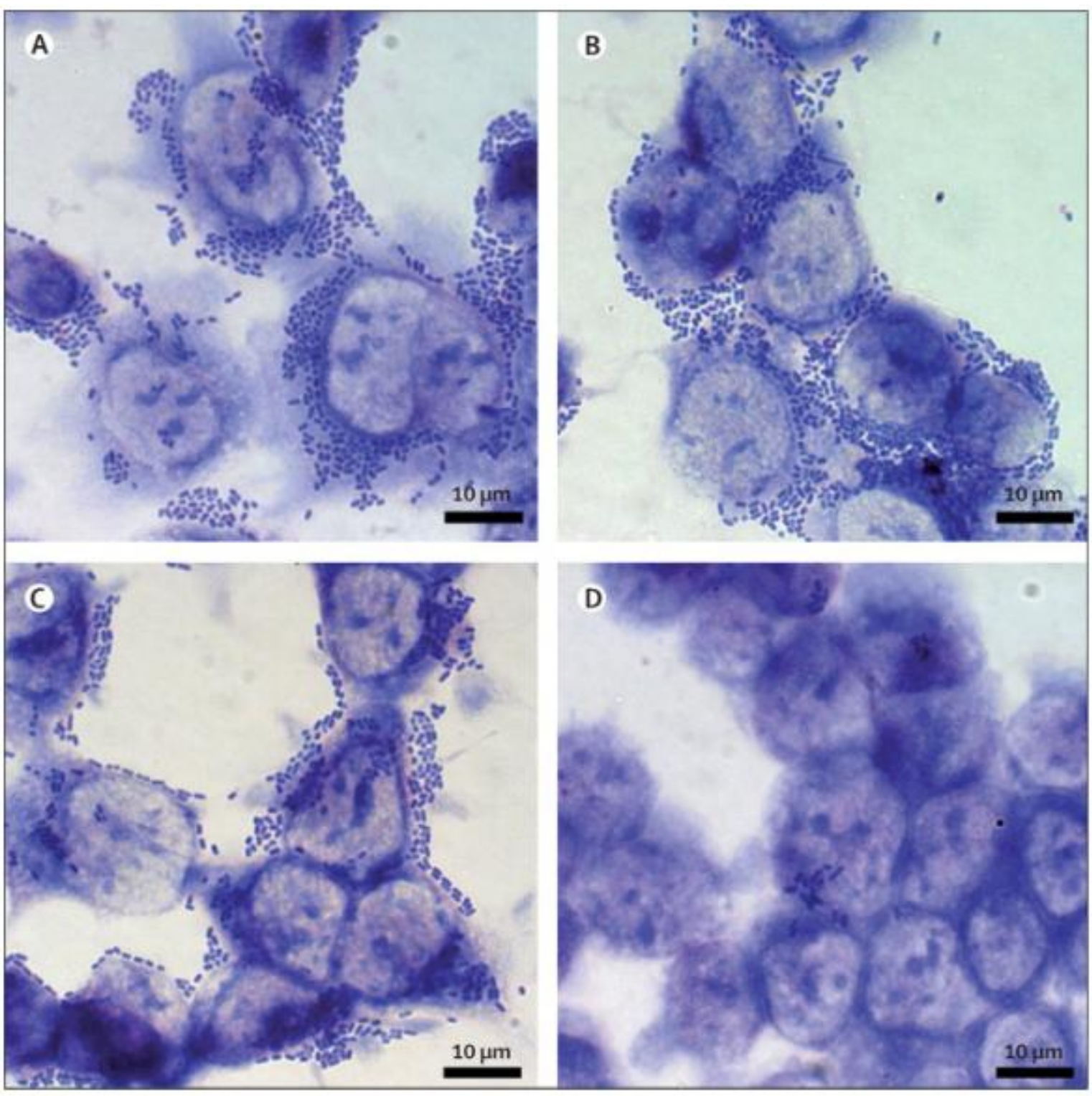

